\title{
Impact of COVID 19 Pandemic on the Quality of Life of Migrant Slum Dwellers of India: a Qualitative Study in Delhi State
}

NIVEDITA ROY ( $\sim$ roynivedita17@gmail.com )

Research Scholar, OPJS University, Near Sankhu Fort, Jhunjhunu Road

\section{Research}

Keywords: COVID 19, migrant workers, anxiety, stress, financial hardships, livelihood, socio-economic crisis, marginalized

Posted Date: September 23rd, 2021

DOl: https://doi.org/10.21203/rs.3.rs-915554/v1

License: (a) (i) This work is licensed under a Creative Commons Attribution 4.0 International License.

Read Full License 


\section{Abstract}

Background: During the COVID pandemic, migrant workers had experienced harsh livelihood and socioeconomic crises which amplified their challenges of life and significantly affected their mental health. However, there is a lack of in-depth evidence on how the mental trauma and shock of the loss of job and livelihood crisis affected men and women migrant workers differently. This study aimed to explore the impact of the COVID pandemic and lockdown on migrant workers who had faced psycho-social and financial challenges during the pandemic and lockdown and the effects of these challenges on their health.

Methods: A formative research method comprising of iterative approach was used by conducting indepth interviews of men and women migrant workers residing in randomly selected 2 blocks of a slum called Madanpur Khadar JJ Colony of Delhi, India. The respondents were chosen using a respondent driven purposive sampling depending on those who had faced severe loss during the pandemic. The migrant workers were interviewed about their challenges until saturation point was reached. In total 25 men and 25 women migrant workers were interviewed.

Results: The financial constraints due to loss of employment, closing down of small scale self employment ventures, salary cuts and loans, threw life out of gear, further marginalizing the already disadvantaged community, who live from hand to mouth. To further aggravate the damage, COVID brought with it social stigma, discrimination, fear, stress, and anxiety. Women migrant workers bore the brunt of the burden of household responsibilities, increased demand without support and emotional abuse at home.

Conclusions: There is an urgent need for unified social protection system with preventive, promotionstricken, protective, and transformational measures designed through a crisis-responsive lens is required to provide an ecosystem of support to migrant workers.

\section{Background}

A sudden rise in already prevalent socio-economic crises in the lives of poor and disadvantaged people has taken place due to the COVID pandemic globally. Out of these marginalized populations, migrant workers constitute perhaps the most severely affected cohort. [3, 4] In the Indian context, the migrant workers faced multiple hardships during the pandemic and lockdown, such as loss of income, [5] food shortages, [6] future uncertainty, [7] and severe mental health challenges. [8-11] India has more than 450 million people in the informal sector, a highly insecure and unregulated sector with few or no social security provisions. [12-14] Poverty and scarcity of food are already an issue for most informal sector migrant workers, but with COVID 19 pandemic, their vulnerability has been multiplied. [15] Moreover, COVID-19 has unevenly impacted women migrant workers severely in the domains of health, economy, social protection, and gender-based violence. $[16,17]$ Several surveys of migrant laborers have already been conducted, and it was found that most of them have lost their work, and the pandemic has 
impacted almost half of them negatively with lack of food or supplies. [18] They are acknowledged as crucial to the urban economy, but policy and social security measures have largely neglected them, further disadvantaging their inclusion in India's urban communities. [19, 20]

The two main cities that attract the highest number of migrants are Mumbai and Delhi, respectively. [21, 22] Most migrants in these cities originate from the rural areas of Uttar Pradesh and Bihar, followed by Rajasthan and Madhya Pradesh. [22, 23] They majorly consist of daily-wage laborers mainly working in the manufacturing and construction industries. [24] Women migrant workers are primarily involved in work related to domestic help. [25] They are dependent on daily wages for their living, and in times of such distress, need sympathy and understanding of the community. [26] During times of emergencies and pandemic crises, the migrants are more prone to social, psychological, and emotional trauma in such situations, emanating from fear of neglect by the local community and concerns about their families' well-being and safety in their native places. Many studies have not reported that the lockdown had brought the lives of migrant workers to a standstill, as have they had no work to do, nor were they able to travel back to their native places. $[27,28]$ Moreover, some of them were not able to meet their daily requirements due to financial constraints. The very basic social distancing strategy could not be ensured in this population as they mostly reside in densely populated communities and rooms with minimal space per person. $[29,30]$

Migrant workers who stayed back in their urban settlements encountered several experiences [31], and these experiences have been documented in several studies. However, the mental health challenges and their implications and effects due to financial loss and others factors have not been explored in-depth

where the migrant workers narrated how the anxiety and stress affected them. Moreover, we currently lack in-depth evidence on how the mental trauma and shock of the loss of job and livelihood crisis affected men and women migrant workers differently. This study aimed to explore, in-depth, the impact of the COVID pandemic and lockdown on migrant workers who remained in their urban settlements during the lockdown and who had faced psycho-social and financial challenges during the pandemic and lockdown.

\section{Methods}

\section{Aim}

The qualitative research study was conducted to understand and interpret experiences, challenges and barriers faced by lower-income group of people who are migrants and working, dwelling in resettlement colonies in these broad fields:

\section{Mental Health \\ 2. Economic condition}

The study further deals with finding out from the migrant workers the ideas of mitigation strategies to overcome the difficulties faced by them that the government can implement for their benefit of overcoming the challenges of livelihood and health. 


\section{Study Setting}

Madanpur Khadar JJ Colony, an urban unauthorized resettlement colony located in the South East Delhi district in Delhi has been chosen randomly from all unauthorized colonies in South East Delhi for the study. southeast Delhi is chosen because of the prevalence of highest percentage proportion of slum dwellers among all districts of Delhi. Current residents of Madanpur Khadar area are first or second generation migrants from the Indian states namely Rajasthan, Uttar Pradesh, Bihar and/or West Bengal. The estimated population is around 25000 , and the majority are Hindus. The residents are mostly engaged as drivers, unskilled laborers, security guards, vendors, construction workers, commercial workers, and the women are mosrlt engaged in factory work, domestic help, street hawking and industrial work. The area consists of 8 blocks in total by random selection 2 blocks had been selected for this study.

\section{Design}

In-depth interview was employed as a qualitative research method. Why In-depth interview?

The basis of formative research stands on two major aspects i.e., How and Why. Questions that start with how and why involve qualitative enquiries that represent 'microscopic' (Geertz, 1973) details of human actions, interactions, and their interpretations. Therefore, such questions involving 'how' and 'why' cannot be quantified rather give freedom to the researcher to reflect and reformulate the research questions in order to acquire relevant information and new findings pertaining to the research. The study was exploratory in nature and accordingly, there was no clear, single set of outcomes (Yin, 1984, p.25). Thus, obtaining narratives on the experiences, worldview and belief systems of the respondents were feasible.

An essential approach adopted during fieldwork and to interpret data was the process of iteration. The idea was to reflect upon each finding to update and improvise research questions to have an understanding of the challenges and experiences of the migrant workers during lockdown and pandemic. It had happened when new information emerged during data collection, which further shaped the interview guide and course of the interview with the interviewees. Taking empirical data/analysis and inductive approach in mind; codes, themes, concepts, and categories emerge on their own from first hand information. The main goal of relying on first hand information was to understand the subjective perspectives than objective understanding and the process was reflexive. Iteration is nothing but a thorough reflexive process, i.e., visiting and revisiting the data back and forth to develop an in-depth understanding of emerging ideas. While themes and sub-themes were in process of emerging from the data, the focus was also on listening to the audio recording, reading field notes and scratch notes while interpreting the data over and over again to understand what data tried to tell and what they wanted to decipher in order to proceed with the interpretation. As a result, new themes emerged. Visits and revisits to the data helped them categorize each data in each subtheme conspicuously, which strengthened the data interpretation. In short, the process of iteration facilitated to interpret the data in a coherent manner to maintain the credibility of the data analysis. 
Data for this research was collected in the year 2020 from 50 second-generation migrant workers residing in the two randomly selected blocks of Madanpur Khadar Colony. The data was collected using Respondent Driven Sampling, which combines snowball sampling with a convenience sampling model. It is a widely used method for sampling from hard-to-reach human populations, including migrants. They were chosen after they were interacted with and found to have immensely suffered psychologically, financially, and socially because of the pandemic and lockdown. The migrant workers were identified to have struggled with anxiety, worry, depression, constant panic, and economic stress based on the snowball sampling method. The length of each interview lasted 40-60 minutes.

Non-Participant Observation- To understand the respondent's symbolic/non-verbal gesture, household items, economic situation, and the concept of hygiene by keenly observing the home environment, which may not be assessed by another method, non-participant observation has been a successful attempt. It helped understand and interpret different perspectives and crosscheck the nuances of what has been shared by the respondent and what has been hidden which was otherwise visible.

\section{Key areas of investigation:}

The study focused on three broad areas of investigation. The key questions explored in the in-depth interviews were as follows:

\section{How was your experience during the Covid lockdown and the peak pandemic situation?}

[Probes:- Any increase in workload, more hours of work compared to pre-lockdown; more arguments, finding faults, bickering, violence, unable to sleep at night; increase in substance abuse, alcohol, smoking, others; by any/male members of family, husband; increased burden due to aggravation of illness of elderly family members, requiring additional time for caregiving; if working outside, whether able to continue]

\section{During the lockdown period, did you ever feel stressed, or anxious? How did you feel?}

[Probe: - Worrying too much, thinking of only the negative, continuous sadness and the associated feelings, feeling of guilt or hopelessness, whether unable to do things you enjoy, changes in sleep pattern like issue in falling or staying asleep or sleeping too much, change in eating habits during lockdown, loss of appetite causing significant weight loss or overeating, physical pain and/or unexplained pain, anxiety, fatigue or other physical symptoms without an apparent cause, problems concentrating or remembering things, losing control over situation, loneliness, isolation, relationship problems with family members, irritability, anger, watching unusually long hours of television/mobile phone, feeling as though life isn't worth living, or having thoughts of suicide]

\section{If situation stressful, what were the main causes of stress; single most important cause and others.}

[Probes: fear of unknown, fear of getting infected, fear of death, uncertainties, financial problems, economic insecurities, no job, pay cut, less or no income; woman ill-treated due to inability to earn during 
lockdown, feeling of low self-esteem, children's education, continuous criticisms and bickering at home, old parents-in-law, own ill-health, pregnancy, any illness of the woman herself, child's/family members ill, health care inaccessible, social isolation, no one to talk to; if infected, the fear of being forcefully taken away to hospital where dead bodies not removed; away from family, fear of discrimination, social stigma]

\section{Did you face any financial difficulties during the pandemic?}

[Probe: how many family members are working to earn a living, did anyone lose job due to the lockdown, consequences- took loan from neighbor/employer/relative, credit card loan, sold household assets/jewelry, exhausted savings/Fixed Deposit (FD), did not have money to buy food, have not paid rent, could not pay for health care, could not buy medicines]

\section{Do you think some actions could be taken (by government, community, others) or alternate arrangements could be made to reduce the sufferings and harassments in leading a good quality of life?}

[Probes: in terms of physical well being, mental well being and social well being, mitigation strategies that the migrant workers could think at their level to avoid terrible situation during another pandemic or another wave of the current pandemic]

\section{Data Analysis}

Data were collected through audio recording with the consent of the respondents. Audio recordings were listened carefully and transcribed to develop codes to develop themes for organizing the findings followed by analysis in NVivo. After each theme with its sub-theme were prepared in NVivo using Nodes, relevant verbatim was extracted from the local language transcriptions and English translation to support findings in each theme and sub-theme. Framework analysis was adopted to analyze the summary of men and women participants' experiences and perspectives. Additionally, it helped to identify common findings and variation in the data to draw descriptive inferences. It also helped to ensure that the analysis equally address the whole datasheet. Transparency while identifying data for each theme was maintained with the help of framework analysis. Not only that, it enabled to document diverse aspects of the phenomenon coherently as well.

\section{Challenges encountered in conducting the study due to COVID and precautions taken}

Initially, when the study was started, the families were apprehensive about interviewers visiting their homes and sitting for long duration inside homes for the in-depth interviews. However, after they were reassured that I am sanitized and am carrying a sanitizer and have put on a double mask, many of them were more comfortable allowing me to enter the households for the interviews, while in some households, the data was collected at the doorstep. All precautionary measures recommended by the government were strictly adhered to in the study by me. I maintained social distancing while conducting the survey and the interviews. During home visits family members I also provided them with masks and made their hands sanitized. All these measures followed by me conveyed a positive message and reassured the families. 


\section{Results}

\section{Psychosocial Impact}

The unprecedented crisis of COVID 19 pandemic has severely impacted the psychological well-being of people. Uncertainty of employment and fear had a massive detrimental impact on the lives of the respondents. From dealing with negative thoughts, financial security, fear of the virus transmission to sleeplessness, losing interest, brooding have considerably worsen respondents' quality of life. The following subthemes have emerged from information gathered in the field.

\section{Fear}

The sudden outbreak of the virus in India and fast information sharing about the nature of the virus and consequences of contracting the virus, including symptoms of fever, cough and cold, shortness of breath, and rapid transmission of the virus triggered fear in the mind of the respondents.

\section{- Fear of being contracted the virus/death}

Five migrant workers whose wife gave birth during lockdown panicked to step out of home, fearing contracting the virus. Furthermore, they were afraid of family members who would go out to get groceries or any other essential items or work to be the carrier of the virus as there was a high chance of people unwittingly spreading the virus in the open air. Few respondents shared that they feared catching the virus and worried about transmitting it within family members. Having said that, two respondents shared that they had experienced severe anxiety and sadness due to the untimely death of their close family members due to the virus.

As reported by the respondents, few had suffered from severe anxiety and sadness due to the sudden death of one of her elderly family members due to COVID 19. Reportedly, the death also made them believe the fact that COVID 19 exists which was not the case with her before the death. During the starting period of the lockdown, they did not believe in the existence of COVID 19 and had a pre-conceived notion that it is a global rumor. She used to think that it is just a viral fever, a normal phenomenon for everyone that happens during season changes. But after her family member's sudden death, she had started to believe in the existence of the disease.

- Fear of discrimination

Almost all migrant workers recalled their bitter experiences while finding for new jobs when they were asked to leave their current job during the pandemic.

I was treated like a worm in a gutter and was called dirty and unhygienic because I used to work as a sweeper of a society. They didn't give me the job because they said I will transmit the disease to them.

They recounted their memories and shared that their experiences were more than social discrimination in our society. Social discrimination itself is a malice in Indian society. Furthermore, the pandemic has 
created an environment that promotes stigmatization that people from lower economic backgrounds lack the sense of hygiene and therefore are prone to transmit virus from one to another, as explained by a respondent. Moreover, the phrase 'social distancing' has become popular, corresponding to discrimination within community, people, and neighbourhood to a large extent.

Besides, all respondents living in a rented place were subjected to verbal abuse, harassment including disconnecting water supply and turning the electricity supply off for hours. Even more significantly, two of the respondents were directly and indirectly asked to vacate the room in the middle of pandemic and lockdown by the landlord. Experiencing such atrocities when they were already going through mental breakdown due to unstable financial condition have severe repercussion on their mental well-being.

- Fear of not getting timely treatment and care

One third of the respondents said that taking infants to the nearby dispensary was the biggest worry for them to expose their infants and children to a vulnerable environment.

Home confinement

When the guidelines on virus protection, including stay-at-home orders; restrictions in travel, restrictions in leisure activities, and restrictions in physical movements, were released by the government, prior lockdown and during lockdown remarkably changed people's mode of life. The family dynamics took a turn. The respondents have mentioned how life has become lonely and monotonous, especially for those rendered jobless. (Fig. 1) Restrictions at public places has been challenging for them to follow as they had to spend most of the time at home. A respondent said his wife tried to cope with her loneliness with sewing as she was more limited with human contacts and pregnant. Not all family members were allowed to come upstairs where she lives and meet her. However, she could not help herself in a confined environment because her family members were restricted from sewing and stitching. They believed such activities could cause the baby to have congenital disabilities. Baby getting born while the respondent is away working in Delhi, especially when a pandemic is still on, was an awful feeling that a respondent recalled. He felt empty inside when he realized he could not be there when her wife and family members needed him most, at the time of delivery and after. In short, loneliness, detachment from others, restrictions in movement, isolation have profoundly affected their mind. As a result, a few respondents disclosed that sometimes loneliness induced loss of appetite.

I get devastated and shattered at the thought of not being there when my child was getting born or when my uncle died due to COVID. I felt stuck here and blamed myself for everything, more so, because I was jobless and couldn't send money home as well.

Anxiety, worry and stress

Anxiety, worry, and stress were largely interconnected with economic uncertainty, unemployment on an individual's mental health. Because all the women in the study were predominantly economically deprived. Economic struggle created impediments for all the respondents who were already living in an 
economically disadvantaged state. The constant panic of the aftermath of exhausting all the money that were borrowed or loaned from bank induced extreme stress in all.

Another considerable reason that escalated anxiety and stress was the emotional breakdown of pregnant women during the pre-lockdown period, during and post-lockdown period. The cause of emotional breakdown was because of increased fear that intensified after gaining information, including the status of spreading the virus via television, from others in the family or community. Those respondents who reported that their wives gave birth or the women respondents who were pregnant just before, during, and post-lockdown feared of exposing infants in such a vulnerable environment. In order to reduce stress and anxiety, these women were barred from watching news, participating in COVID 19 related discussion, or accessing any information related to the virus.

\section{Sleeplessness}

One of the major consequences of anxiety, worry and stress was sleeplessness. Half of the respondents shared that they experienced disturbances in sleep, which they believed happened due to excessive stress regarding several reasons, including financially worried about future; arranging food for children, running expenditure on gas, electricity, and rent. Staying awake at night had severe consequences, especially on women involving weakness, fragile health.

\section{Loss of Productivity}

Anxiety and stress affected the sleeping pattern of respondents and has also significantly weakened interest in doing things that they once loved to do, such as preparing nice meal or delicious snacks, practicing their hobbies, and enjoying good food. However, such state of mind has induced sleep in some cases. Few respondents experienced oversleeping day and night. They lost interest in getting vegetables for family at times, felt lethargic, and fatigue all along. They correlated loss of productivity and fatigue was triggered by incessant fear of financially managing family in upcoming days. As stated by few respondents, those who were staying alone and lonely were also a factor of losing interest in doing things.

\section{Losing patience}

A very crucial factor that negatively influenced the psychological well-being of respondents was loss of patience. One of the respondents shared that not only financial insecurity affected his sleep but his parenting as well. Having found no way to deal with his mental strain and frustration, he realized that he often burst out his anger and frustration by yelling and sometimes beating his toddler child. In another scenario, three respondents revealed that the entire episode of lockdown and the pandemic outbreak wreaked regular lives and affected mentally with exponential fear, which caused them to lose patience and get involved in a bit of disagreements and arguments. They strongly believed that such events would not have happened, if the pandemic didn't hit everyone. 
Data reveal few migrant workers have been found to be severely affected by the lockdown and sudden economic downfall. Anxiety and stress due to losing job, unable to bear the household expenditure, and debt/loan were the primary reasons that elevated negative thoughts including self-destruction. Being the sole earning member of the family dealing with financial insecurities forced them to cost-cutting in spending money which adversely affected their mental health. Few had thoughts of suicide.

I had never thought of committing suicide before, but after the pandemic, my situation is so terrible financially that I think of dying every hour of the day, especially because I can't go home.

Domestic violence reported by female migrant workers

Few women have experienced physical violence and emotional abuse from her husband or other family members in terms of violence. However, almost three-fourths of them (19/25) have shared that they argued over little matters and verbal spats occurred with spouses, which did not happen less in the pastmost of these women go through emotional abuse at the time of lockdown. Few women also reported domestic violence, especially physical violence, increased during the lockdown, especially after losing their job. Only a few (4/25) knew the sources of seeking help through telephone or visiting a place if someone experiences domestic violence. The enhanced severity of domestic violence during the pandemic had imposed severe mental trauma for these women and caused them severe loss of appetite and sleeplessness.

Before this (lockdown) he (husband) would slap me, but now he hits me with belts and sticks sometimes. I try to stay strong only for my child but I die inside slowly and every day.

\section{Financial challenges}

A complex Venn diagram in Fig. 2 is showing the correlation between sudden unemployment or substantial pay cuts and its effects or impacts on migrant workers. The circles with deeper shade are the effects reported at a large scale. The circles with a lighter shade are the effects reported on a small scale.

Detailed risk analyses (Table 1) of the risk and effects of livelihood due to financial crisis have been given in detail in the table below. This table includes information on challenges experienced in eating food and buying basic products of daily needs for survival on a daily basis, challenges experienced in shelter, especially for migrants who reported that they stay in rent, challenges experienced in meeting the daily needs of their children at home and their education, challenges experienced in practicing the COVID precautions and WASH. Almost all the respondents appeared to be tired of spending money on COVID 19 hygiene products. Few respondents found it luxury while the others perceived maintaining precautionary measures an additional burden on expenditure but necessary which cannot be ignored. In terms of struggling to make ends meet, from the findings, it can be said that all the respondents reduced household requirements and expenditure. What they did not comprise on was infant's food and health care in some cases. In some cases, the respondents cut down their food consumption in trying to save for children. 
Table 1

Risk analysis of financial challenges affecting livelihood

Risk Effects Existing Controls

Complete loss of job or huge pay cuts at work affecting livelihood
Unable to pay rent

Shattering of city dreams and leaving rented house to migration to own house in the village

Unable to make ends meet
Borrowing from family/friends

Begging for a seat in the Gramin Seva autos/buses/ambassadors that were available or walking
Minimal expenditure on household utilities and
ration

Depended on govt ration and everyday food parcel

Waited for the free milk packets that were sometimes distributed in the locality so that the children could have milk.

Children dropping out from school

Admitting their children in the local MCD schools

Selling off assets in the house

Not giving much priority in buying masks and sanitizers because of their costs.

Starting small scale jobs like tailoring, making flower garlands, and other similar work to ensure the children meet their daily requirements

Not being able to maintain WASH in the surroundings of the house

Survived on the free kits that were sometimes getting distributed in the school of the locality. The kits had soap and masks.

Severe anxiety and depression due to financial crisis and no savings to compensate for the sudden loss of job

Decrease in a healthy relationship with bank/relatives/friends/close acquaintances from whom the debt was taken
Moral support from spouse and other family members
Rolling of money by asking other relatives/friends/acquaintances to lend money so that they can pay back the money borrowed from bank or previous relatives/friends/close acquaintances

Selling of land or other properties owned by the Selling
family

Respondents talking about struggles to make ends meet:

Minimizing the food intake: We mostly ate one-time meals daily after my job was gone. Making ends meet became difficult. 
Borrowing for eating food: I borrowed milk from the neighboring grocery shop to feed my small child at home. I still need to repay the money back.

In terms of household utilities, reportedly all women, mostly who were staying on rent, had compromised on buying household items and mostly used the previous savings or borrowed money for food for children and their own selves. Few respondents said they postponed spending on necessary household items, including bed, painting rooms, repairing stairs, buying an almirah, and getting a motorcycle due to financial breakdown. Rest of the respondents felt they could buy items like utensils, clothes, or repair household appliances later when the situation normalizes and life gets back to normal without lockdown or COVID outbreak.

Most migrant workers stay with their families in rented accommodation in the urban enclaves and are deprived of the eligibility of receiving ration card from the Public Distribution System. [32] Table 2 shows the key existing controls for the various effects of the risk of sudden unemployment and their implementation as reported by the respondents staying in a rented house and own house irrespective of whether joint family or nuclear family.

Table 2

Key existing controls for the various effects of the risk of sudden unemployment and their implementation as reported by the respondents staying in a rented house and own house

\begin{tabular}{|c|c|c|c|}
\hline Key Existing controls & $\begin{array}{l}\text { Rented } \\
\text { house } \\
\text { (out of } \\
\text { 29) }\end{array}$ & $\begin{array}{l}\text { Own } \\
\text { house } \\
\text { (out of } \\
11 \text { ) }\end{array}$ & $\begin{array}{l}\text { Total } \\
-40\end{array}$ \\
\hline Borrowing from family/friends/acquaintance & 23 & 10 & 33 \\
\hline Minimal expenditure on household utilities and ration & 23 & 6 & 29 \\
\hline $\begin{array}{l}\text { Depended on govt ration and everyday food parcel that was getting } \\
\text { distributed }\end{array}$ & 12 & 11 & 23 \\
\hline Made the children drop out of school because unable to pay fees & 10 & 3 & 13 \\
\hline Selling off assets in the house for having the money for daily survival & 19 & 5 & 24 \\
\hline $\begin{array}{l}\text { Starting small scale jobs like tailoring, making flower garlands, etc. to } \\
\text { ensure the children meet their daily requirements }\end{array}$ & 17 & 3 & 20 \\
\hline $\begin{array}{l}\text { Moral support from spouse and other family members to avoid severe } \\
\text { anxiety and depression }\end{array}$ & 5 & 11 & 16 \\
\hline $\begin{array}{l}\text { Rolling of money by asking other relatives/friends/acquaintances to } \\
\text { lend money so that they can pay back the money borrowed from bank } \\
\text { or previous relatives/friends/close acquaintances }\end{array}$ & 28 & 9 & 37 \\
\hline
\end{tabular}

From the above table, it could be noted that the respondents who reported that they stay in a rented house had faced more problems than the ones with their own house, like, just making daily ends meet, 
including food and daily utilities. They had to borrow money mostly from other people and mostly depended on government-provided online ration cards (E-coupon) to survive because the rented households do not get ration cards. Only the households who own the house are eligible for a ration card for staples at a very low price. Few migrant workers also reported that they did not receive the E-coupon for the one-time ration provided by the Delhi government. Similarly, women reportedly staying in rented houses started opening small scale businesses with complete support from their spouses to support the family financially to meet the daily requirements of their children and themselves.

\section{Mitigation}

As a part of the risk analysis, which always includes risk, effects/impacts, existing controls and mitigation, the mitigations for all the effects of the risks have been noted (Table 3 ). These mitigation strategies were reported by the migrant workers who were interviewed when asked about what solutions have they thought of which could benefit them and make them avoid the risks associated with degrading livelihood and quality of life to the utmost possibility. 
Table 3

Mitigation strategies as reported by the migrant workers

Effects

Unable to pay rent

Existing Controls

Borrowing from family/friends

Begging for a seat in the

Gramin Seva

autos/buses/ambassadors that

were available or walking

village

Unable to make ends meet

Minimal expenditure on

household utilities and ration

Depended on govt ration and

everyday food parcel

\section{Mitigation}

Allow the tenants some time to pay rent. The landlords should not ask for rent and be rude to them.

There should have been proper transport facilities at least for the families who wanted to go back to their own house in the village.

At least those who are staying in rent should have got the provision to get ration through e-coupon at least once a month. Reportedly they have received only once in the entire tenure of the lockdown, which did not help much.

Children dropping out from school

Not giving much priority in buying masks and sanitizers because of their costs
Admitting their children in the local MCD schools

Selling of assets in the house

Starting small scale jobs like tailoring, making flower garlands, etc. to ensure the children meets their daily requirements

Severe anxiety and depression due to financial crisis and no savings to compensate for sudden loss of job
Moral support from spouse and other family members
The schools should have been considerate about not making their students drop out who are unable to pay rent.

Sanitizers and masks can be distributed free of cost for a couple of months.
Encouragement of keeping oneself busy with indulging in different ways to earn money
Decrease in healthy relationship with bank/relatives/friends/close acquaintances from whom debt was taken
Rolling of money by asking other relatives/friends/acquaintances to lend money so that they can pay back the money borrowed from bank or previous relatives/friends/close acquaintances

Selling of land or other properties owned by the family

\section{Discussion}

The COVID-19 pandemic had inescapable impacts on people across the globe. The marginalized segments of the population, however, have been severely affected by COVID pandemic. The vulnerability of migrant workers in countries like India is already an issue of grave concern. The financial constraints 
due to loss of employment, closing down of small scale self employment ventures, salary cuts and loans, threw life out of gear, further marginalizing the already disadvantaged community, who live from hand to mouth. Daily survival was nothing less than a nightmare for the families who did not have safety nets of financial buffers.

To further aggravate the damage, COVID brought with it social stigma, discrimination, fear, stress, and anxiety. [33] Home confinement over months together in matchbox accommodations deteriorated living conditions and mental health. Women migrant workers bore the brunt of the burden of household responsibilities, increased demand without support and emotional abuse at home. [34] Additionally, the rise in domestic violence against women is perhaps the biggest setback to women's rights. The pandemic has revealed the injustice faced by women in the most glaring way possible. It is pivotal to put women's rights at the forefront of policies and identify their vulnerabilities using gender as a lens.

Regarding the financial challenges, the migrants proposed that the government should have mandatory regulations for landlords to waive off or allow delay in house rent payments, government should provide subsidized or free rations for poor families, arrange for zero-interest loan facilities, provide masks and those with school-going children, requested waiving off of fees in private schools and few mentioned temporary access to smartphones for online classes, at least on rent.

The pandemic's impact led the government to expand existing social protection schemes and introduce new measures to protect livelihoods. [36] Employment and food security were also targeted by extending provisions under flagship schemes, such as the Mahatma Gandhi National Rural Employment Guarantee Act (MGNREGA) [37] and the Public Distribution System (PDS). [38] However, there is a need to minimize the exclusion of migrant workers from the social protection schemes. Given the widespread lack of basic amenities for migrant workers stranded in urban centers, massive unemployment, and the importance of minimizing out-of-pocket expenditures on health, the government is required to give them access to social protection measures like food security, financial support, and government health insurance schemes.

Apart from this, the mental exhaustion and trauma that the migrant workers go through and the effects of the trauma, stress, and anxiety renders them to long term psychological and mental illnesses. The impact of anxiety on sleep, appetite, thoughts, and lifestyle is found to be highly negative and needs immediate focus from the health system point of view. Immediate measures can be tele-counselling by psychotherapists and mental health counselors and in-person counseling by home visit or inviting the migrant residents to a place of counseling. [39] Group discussions can also help them open up to express their experiences as it can help their negative feelings subside.

\section{Conclusion}

An unified social protection system with preventive, promotion-stricken, protective, and transformational measures designed through a crisis-responsive lens is required to provide an ecosystem of support to migrant workers. Access to social protection benefits beyond state borders is essential to compensate for 
the misfortunes and impediment they have experienced as a result of the ongoing crisis. The creation of such a specialized system of social protection for migrant workers

\section{Abbreviations}

JJ - Juggi-Jhopri, COVID - Coronavirus Disease 2019, FD - Fixed Deposit, WASH - water, sanitation and hygiene, MCD - Municipal Corporation of Delhi, E-coupon - Electronic coupon

\section{Declarations}

Ethics approval and consent to participate - Verbal consents were taken from the respondents to participate and interview as well as an audio recording of conversations.

1. They were explained the need of audio recording for the researchers.

2. They were also assured that data would be kept confidential and used for research purposes.

3. They were confirmed that their identity would be hidden and no names will be appeared in any report.

4. They were told that the all the recordings would be deleted once data analysis was done.

5. Verbatim used in the report kept anonymous.

Consent for publication - The consent for publication of the findings had been taken from the study participants.

Availability of data and materials - The data underlying this article will be shared on reasonable request to the corresponding author. Anonymized forms of these data will be available on request from the corresponding author

Competing interests - There is no competing interest for this article as there is only one author for this article.

Funding - The author did not receive any funding for this article.

\section{Acknowledgements - NA}

\section{References}

1. Hamiduzzaman M, Islam MR. Save life or livelihood: Responses to COVID-19 among South-Asian poor communities. Local Development Society. 2020. DOI:10.1080/26883597.2020.1801334.

2. Laura F, Piper N. COVID-19 and Women Migrant Workers: Impacts and Implications. Geneva: InternationalOrganization for Migration; 2020. 45 p. Accessed from: https://publications.iom.int/system/files/pdf/the-gender-dimensions-of-the-labour-migration.pdf. 
3. Che L, Du H, Chan KW. Unequal Pain: A Sketch of the Impact of the COVID-19 Pandemic on Migrants' Employment in China. Eurasian Geogr Econ. 2020. doi:10.1080/15387216.2020.1791726.

4. Azeez AEP. Stay at Home' but Home Is Away: Plight of Migrant Workers. The Eastern Herald. 4 May 2020. Accessed 20 September 2020. https://www.easternherald.com/op-ed/plight-of-indian-migrantworkers-63055/.

5. IHRB. Migrant Voices: Stories of India's Internal Migrant Workers during the COVID-19 Pandemic. In: Institute for Human Right and Business. 2020. https://www.ihrb.org/focus-areas/migrantworkers/india-internal-migrant-workerscovid-19. Accessed 15 Jan 2021.

6. Dahir LA. Instead of Coronavirus, the Hunger Will Kill Us. A Global Food Crisis Looms. The New York Times. 22 April 2020. https://www.nytimes.com/2020/04/22/world/africa/coronavirus-hungercrisis.html. Accessed 20 March 2020.

7. Pandey G. Coronavirus in India: Desperate migrant workers trapped in lockdown. BBC. 22 April 2020. Coronavirus in India: Desperate migrant workers trapped in lockdown - BBC News. Accessed 9 August 2020.

8. Choudhari R. COVID 19 pandemic: Mental health challenges of internal migrant workers of India. Asian journal of psychiatry. 2020. DOI:10.1016/j.ajp.2020.102254.

9. Kumar K, Mehra A, Sahoo S, Nehra R, Grover S. The psychological impact of COVID-19 pandemic and lockdown on the migrant workers: A cross-sectional survey. Asian journal of psychiatry. 2020. DOI:10.1016/j.ajp.2020.102252.

10. Chander R, Murugesan M, Ritish $D$, et al. Addressing the mental health concerns of migrant workers during the COVID-19 pandemic: An experiential account. International Journal of Social Psychiatry June. 2020. doi:10.1177/0020764020937736.

11. Chatterjee K, Dangi A, Prakash J, Srivastava K, Chauhan V, Yadav P. Coping with the aftermath of COVID: Industrial resurgence, mental health, and resilience. Industrial psychiatry journal. 2021. DOI:10.4103/ipj.ipj_20_21.

12. Sengupta S, Jha MK. Social Policy. COVID-19 and Impoverished Migrants: Challenges and Prospects in Locked-down India. The International Journal of Community Social Development. 2020. DOI:10.1177/2516602620933715.

13. Rao N, Narain N, Chakraborty S, et al. Destinations Matter: Social Policy and Migrant Workers in the Times of Covid. Eur J Dev Res. 2020. DOI:10.1057/s41287-020-00326-4.

14. Pandey S. Social Security for Migrant Workers during COVID-19. EPW. 2020. Social Security for Migrant Workers during COVID-19 | Economic and Political Weekly (epw.in). Accessed 19 December 2020.

15. Indian migrant workers during the COVID-19 pandemic. Wikipedia. 2020. Indian migrant workers during the COVID-19 pandemic - Wikipedia. Accessed 13 Feb 2021.

16. Laura F, Piper N. COVID-19 and Women Migrant Workers: Impacts and Implications. Geneva: InternationalOrganization for Migration; 2020. 45 p. Accessed from: https://publications.iom.int/system/files/pdf/the-gender-dimensions-of-the-labour-migration.pdf. 
17. Guha-Khasnobis B, Chandna S. Socio-Economic Impact of COVID-19 on Women Migrant Workers. Development Futures Series. UNDP Global Policy Network Brief. June 2021. UNDP-DFS-SocioEconomic-Impact-of-COVID-19-on-Women-Migrant-Workers.pdf. Accessed 3 September 2021.

18. Khanna A. Impact of Migration of Labour Force Due to Global COVID-19 Pandemic with Reference to India. Journal of Health Management. 2020. DOI:10.1177/0972063420935542.

19. Pachauri S. COVID-19 Outbreak Brings Attention Back to Informal Sector. Down to Earth. 23 March 2020. https://www.downtoearth.org.in/blog/urbanisation/COVID-19-outbreak-brings-attention-backto-informal-sector-69947. Accessed 11 September 2020.

20. Power K. The COVID-19 Pandemic Has Increased the Care Burden of Women and Families. Sustainability: Science, Practice and Policy. 2020. DOI:10.1080/15487733.2020.1776561.

21. Das KC, Saha S. Inter-state migration and regional disparities in India. Conference Proceeding. Population Association of America Annual Meeting. 2013. Microsoft Word - Inter-state migration_IUSSP13. Accessed 12 January 2021.

22. Jha A, Kawoosa VM. What the 2011 census data on migration tells us. Hindustan Times. 26 July 2019. What the 2011 census data on migration tells us | Latest News India - Hindustan Times. Accessed 18 August 2020.

23. Kumar A, Kumar M. Marginalized Migrants and Bihar as an Area of Origin. 2020; 55(24). URL: Marginalised Migrants and Bihar as an Area of Origin I Economic and Political Weekly (epw.in).

24. Srivastava R, Sutradhar R. Labour Migration to the Construction Sector in India and its Impact on Rural Poverty. Indian J Hum Dev. 2016. doi:10.1177/0973703016648028.

25. Madhubani M. Migration for domestic work-a case of female domestic workers in Bangalore. International Journal of Social Science Interdisciplinary Research. 2013;2(1):44-61.

26. Hargreaves S, Rustage K, Nellums LB, McAlpine A, Pocock N, Devakumar D. et.al. Occupational health outcomes among international migrant workers: a systematic review and meta-analysis. Lancet Glob Health. 2019. DOI:10.1016/S2214-109X(19)30204-9.

27. Rajani S, James J, Balraju RSJ. Migrant Workers at Crossroads-The COVID-19 Pandemic and the Migrant Experience in India. Social Work in Public Health. 2020. doi:10.1080/19371918.2020.1808552.

28. Chakraborty S. 2020. Increased Care Work, Reduced Wages: Informal Women Workers are Rarely Getting By. The Wire. 25 May 2020. https://thewire.in/women/women-informal-workers-lockdown. Accessed 12 September 2020.

29. Srivastava R, Nagaraj A. As migrant workers struggle for lockdown aid, India seeks to count them. Reuters. 29 April 2020. As migrant workers struggle for lockdown aid, India seeks to count them I Reuters Accessed 17 May 2020.

30. Bhowmick N. They treat us like stray dogs': Migrant workers flee India's cities. National Geographic. Khandelwal, Saumya. 27 May 2020. 'They treat us like stray dogs': Migrant workers flee India's cities (nationalgeographic.com). Accessed 27 May2020. 
31. Sampath G. The migrant worker as a ghost among citizens. The Hindu. November 25. 2020. The migrant worker as a ghost among citizens - The Hindu. Accessed 19 December 2020.

32. Dejouhanet L, Rémi DB. New Geographies of Collection: Crossed perspectives on modern "gatherers", EchoGéo [Online]. 2019. DOI: https://doi.org/10.4000/echogeo.16477.

33. Nations U. Policy Brief: The Impact of COVID-19 on Women. 9 April 2020.

https://www.un.org/sexualviolenceinconflict/wp-content/uploads/2020/06/report/policy-brief-theimpact-of-COVID-19-on-women/policy-brief-the-impact-of-COVID-19-on-women-en-1.pdf. Accessed 15 September 2020.

34. Varshney M, Parel JT, Raizada N, Sarin SK. Initial Psychological Impact of COVID-19 and Its Correlates in Indian Community: An Online (FEEL-COVID) Survey. Plus One15. 2020. doi:10.1371/journal.pone.0233874.

35. Geetika, Singh T, Gupta A. Women Working in Informal Sector in India: A Saga of Lopsided Utilization of Human Capital. International Proceedings of Economics Development and Research. 2011;4:p534-538.

36. Government of India. Ayushman Bharat. Official Website Ayushman Bharat | PMJAY | National Health Authority. Accessed August 122020.

37. Government of India. Mahatma Gandhi NREGA. Mahatma Gandhi NREGA | Ministry of Rural Development, Government Of India. Accessed August 122020.

38. Government of India. Welcome to Public Distribution System(PDS) (eds.nic.in). Accessed August 19 2020.

39. Simpson S, Richardson L, Pietrabissa G, Castelnuovo G, Reid C. Videotherapy and therapeutic alliance in the age of COVID-19. Clinical Psychology Psychotherapy. 2021;28(2):409-21.

\section{Figures}

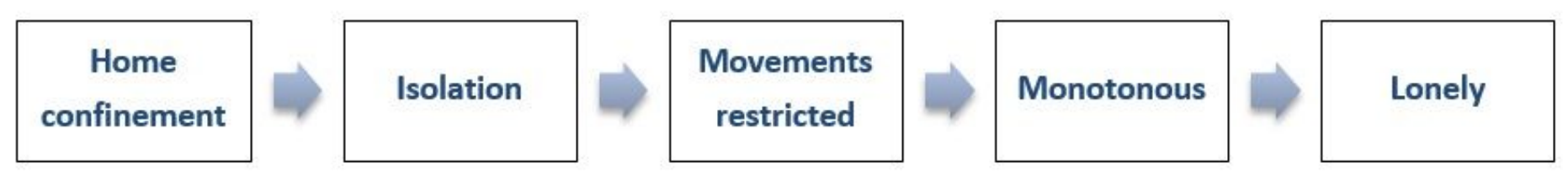

Figure 1

Effects of Home Confinement 


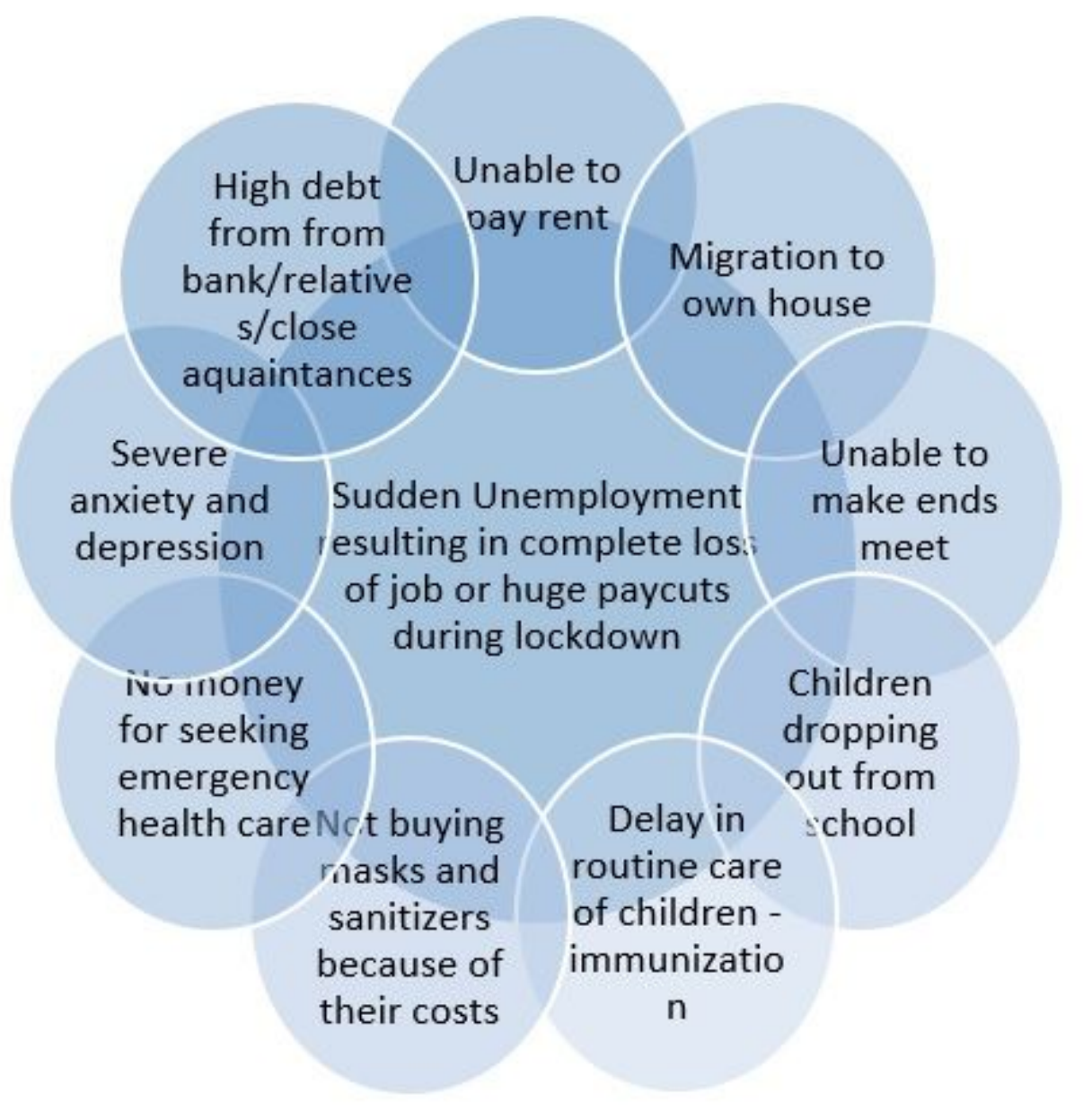

Figure 2

Venn diagram showing a correlation between sudden unemployment or substantial pay cuts and its effects or impacts on the migrant workers 